\title{
Do Students Listen To Advice From Their Experienced Peers?
}

Joseph E. Finck, Central Michigan University, USA

Amy D. DeLine, Central Michigan University, USA

\begin{abstract}
How students use advice from the previous class is analyzed and reveals more than just the value passing suggestions from one class to the next.
\end{abstract}

\section{INTRODUCTION}

esearch on the first day of class by Knefelkamp (Rubin, 1985) showed there was a real desire on the
part of both students and teachers for connectedness, but neither group realized the other shared that
desire.

"If the participants on both sides don't understand how to develop their relationships, learning will be diminished. If you have experienced some anxiety about this meeting, planning some specific steps can not only reduce that feeling, but can get students to share in the sense of purpose you hold for the class."

In a previous paper (DeLine \& Finck, 2008) we presented a way to address, before the first day of class, the desire of students to learn about a class and instructor, and the need of faculty to let the students know what the expectations are for his or her class. That publication showed how students, who have taken one or two semesters of a class from a professor, can give advice to the following class. We showed how his student-to-student guidance can be easily distributed using classroom management programs, such as BlackBoard.com ${ }^{\mathrm{TM}}$. This new practice was compared to institutionally administered teacher evaluations and popular student websites, such as RateMyProfessors.com ${ }^{\mathrm{TM}}$.

Smith and Peterson (2007) recognize the impact between students seeking out advice and that student's academic performance. And Sallee and Tierney (2007) considered the ways in which students' peer networks facilitate or inhibit access to academic resources. In this paper we look at the students who receive suggestions from the previous class. Do they read the advice from their experienced peers? What advice do they follow? What advice do they wish they had followed? Do their responses suggest any instructional areas that faculty need to address?

\section{RESULTS FROM PREVIOUS STUDY}

Even before the students walk into the classroom, they can discover the reputation of the professor or course from a number of sources. Students who have previously taken the course or professor have always freely relayed their experiences to future students. However, their advice may be skewed since the same professor may use different teaching styles from course to course and may adjust any course from time to time. Also, each student gains a different perspective and will give a future student an opinion biased by their experience, workload and grade. Anecdotally, all educators can point to professors who they admired, while they know some of their peers had unsatisfactory experiences with the same individual. And just as often the reverse was true. Finally, word of mouth information is inherently unreliable because the sample size is usually so small.

The most popular resource now available to students to find information about a future professor and course is a professor evaluation website such as RateMyProfessors.com (RMP) or similar on-line internet sites. The 
popularity of RMP is undeniable. There have been 5.7 million submissions of 770,000 professors in nearly 6000 schools from the beginning of RMP.com until August 2006 (Otto et al., 2007). Students can quickly go to the website and look up a professor they are considering taking for a class, and discover what other students have said about the professor. "A primary reason for the popularity of online teacher rating sites is, arguably, students' desire for information about classes and professors. Unlike traditional course evaluations where the audience is the teacher and perhaps administrators, the intended audience for RMP and other similar sites is other students (Kindred and Mohammed, 2005)."

In focus group studies by Kindred and Mohammed (2005) students showed they were wary of trusting the evaluations at RMP, but continued to use them as a supplement. Clearly, they want as much information about courses and teachers as they can get, even if the source is somewhat questionable. Kindred and Mohammed also reported that students rely more on the written over the non-written portion of the evaluations. RMP can be a useful website for students. They can get a feel for what the professor is like before walking into the classroom. However, the information provided is not as reliable as many students may think. Students can make multiple submissions, either on purpose or by accident. Students may forget whether they have evaluated a professor and may make double remarks, while others may try to lift up or bring down a professor's ratings by commenting twice.

Also, bogus comments are possible since professors can rate themselves and their colleagues (Montell, 2006). Since students do not need to have a login ID to rate a professor, it makes it difficult to track who made which comment and it is therefore subject to a number of different types of abuse. However, not requiring an e-mail address allows students to make comments anonymously without having to worry about a professor or other students who read their comments. It is not likely that professors regularly make their own comments, or make comments on their colleagues' sites, but it is possible that it happens without anyone's awareness. In general, it can be abused in many different ways, even just to be funny. While the results can be frank and sincere, they are not necessarily representative of those who have actually taken the course.

Further problems result when, just like with student opinion forms, students tend to vent without providing useful information about the course or the professor. If a student is very pleased with the professor's teaching or very angry at the professor, he or she is more likely to make a comment on RMP than someone who had an average experience (Davison, 2006).

The biggest drawback of RMP is that it does not provide a statistically valid or representative sample of students (Cooladarci \& Kornfield, 2007). For example, one of the authors of this paper (JF) has taught over 700 students over the past three years. During this time only 21 postings have been made on RMP. In addition, only students who feel compelled to post on RMP are represented. So the students who respond on RMP are not only a small sample, but they are also a skewed sample.

Student evaluations of their university classroom experience have been conducted and the subject of academic studies since at least the 1920's (Remmers, 1927). "No method of evaluating college teaching has been researched more than student evaluations, with well over 2,000 studies referenced in the ERIC system. The preponderance of these study results has been positive, concluding that the evaluations are: (a) reliable and stable; (b) valid when compared with student learning and other indicators of effective teaching; (c) multidimensional in terms of what they assess; (d) useful in improving teaching; and (e) only minimally affected by various course, teacher, or student characteristics that could bias results (Centra, 2003)."

Many studies (cf. Hobson and Talbot, 2001; Cooladarci, T. \& Kornfield, 2007 and references contained therein) reviewed research on the reliability and validity of student evaluations and concluded that "well-developed student evaluations with adequate reliability and validity data may provide some of the best measures of teaching effectiveness." In spite of this research, it is not uncommon to find students who doubt value of these university administered evaluations (Ahmadi et al., 2001). Similarly, many faculty doubt the ability of these instruments to measure their teaching. 
The primary audiences for the student evaluations are the professor, deans and personnel committees. Ideally, instructors will use this feedback to improve their instruction and the courses they teach. And the hope is that those evaluating faculty for promotion and tenure will carefully examine all aspects of these surveys and be aware of research that support their validity. However, students may only fill out the multiple choice section of the evaluation and skip the more revealing essay portion. Furthermore, while the written comments are given to the instructor, it is common for chairs, deans and personnel committees to receive only summaries of the responses to the multiple choice questions. As a result, the evaluations are frequently reduced to one or a few numbers that attempt to average all the multiple choice responses. This is similar to the RMP web site which uses hot peppers, smiley and frowny faces to summarize a professor's evaluation.

While RMP is designed for a student audience; university administered evaluations of teaching are not. There is a wealth of research on the reliability and validity of traditional teaching evaluation; there are many recent publications that focus on the flaws of RMP. The logical question is: Why not make universities developed and administered student teaching evaluations available to the students?

Although some colleges now make such information publicly available, many more still do not (Kindred and Mohammed 2005). Central Michigan University is one of the few to permit students to access student opinion surveys. However, the availability of the evaluations is not well-known, obtaining the material is not convenient, and not all information is shared with the students. An informal poll of over a hundred students of one of the authors of this paper (JF) revealed that none of them knew they were permitted access to student opinion surveys. Even if they were aware of this, the students would have discovered that the information must be checked out from the reserve desk at the library. After signing a check-out form, the students would be given a cd and instructed to search for a professor of interest. The information they would eventually access is the same that is available to the deans: no written student comments and average scores on the multiple choice questions. Students have always had a desire for information about their potential classes and instructors. Today's students are accustomed to accessing information immediately and with ease. This combination assures continued use of internet sites like RMP.

At the end of second semester of College Physics II (PHY 131), one of the authors (JF) has added an additional question to the essay portion of the student evaluation form. It asks, "What advice would you give to students taking College Physics I (PHY 130) next semester?" After grades are submitted all the written responses to the student opinion survey are given to the faculty member. Over ninety-percent of the students voluntarily provide this advice. For the last three years the response to this additional question have been compiled and the week before the start of the upcoming semester, this advice is passed on to the students who are about to begin their physics education in college.

The vehicles used to pass on this advice are BlackBoard ${ }^{\mathrm{TM}}$ and the World Wide Web. At Central Michigan University students start to enroll in October for the semester beginning in January. From the start of this enrollment process, faculty have access to their class lists. So all the advice written in December by the College Physics II class is distributed to the College Physics I class during the first week of January via BlackBoard ${ }^{\mathrm{TM}}$. In addition, this is an opportunity to send the students a message of welcome from the professor, which points them to an online syllabus (so they see policies and organization before they come to their first class).

Limited editing is done to the advice that is passed from the experienced class to the incoming class. No editing is done to poor grammar, and misspellings are never corrected. However, any profane remarks are replaced with characters such as $\$^{\wedge} \# \%$ and no names of students of any other faculty make it into the final copy. Finally, almost all physics lectures always are accompanied by demonstrations. There are a number of students that give general advice, such as, "Watch out for flying objects," but anything more specific could ruin the drama, element of surprise or the purpose of the demonstration. Such remarks that give away secrets of demonstrations are deleted. Usually, only a few comments need editing and the future students receive unfiltered and sincere comments from their predecessors.

Table 1 gives the most common comments made by the college physics students in response to the "give future students advice" question and in RMP. The distinction is that in the first case the students are clearly 
speaking to future students and giving them advice on how to succeed, while RMP comments focus on the good and bad qualities of the teacher and how to get by with the least amount of effort.

It is important to recognize the number of students who participate in the three different teacher evaluation formats discussed in this paper. For the university administered student opinion surveys the maximum number of responses is determined primarily by the attendance on the day the evaluations are conducted. For the three classes examined here the attendance and response rate was 70-80 percent. For two of the classes ninety-percent of these students also submitted advice to future students, and for the 2004 class, every student who filled out a student opinion survey provided advice. Indeed, for all three classes more students responded to the "advice" question than responded to the three other "essay" questions on the student opinion survey. By comparison, over the same three years fewer than three percent of these same students elected to post a comment on RateMyProfessors.com.

Table 1 displays a summary of the most frequent comments made by the students. One must be impressed with these students. The most common advice they give is exactly what their professor would tell incoming students: do the homework and do it in advance of the deadlines; go to class every day; take advantage of the sample exams provided; find study "buddies"; and make use of the professor's office hours and help room services. The only ambiguous advice that appears year after year regards the textbook. This reaction to a textbook is probably not surprising to any faculty member.

\begin{tabular}{|c|c|c|c|c|}
\hline \multicolumn{5}{|c|}{$\begin{array}{r}\text { Table } 1 \\
\text { Summary of the ten most common pieces of advice }\end{array}$} \\
\hline $\begin{array}{c}\text { Advice } \\
\end{array}$ & $2004(\mathrm{~N}=68)$ & $2005(N=67)$ & $2006(\mathrm{~N}=56)$ & Total $(\mathrm{N}=191)$ \\
\hline Do all of the homework & 20 & 31 & 38 & 89 \\
\hline Do not procrastinate with homework & 27 & 30 & 25 & 82 \\
\hline Go to class every day & 17 & 34 & 26 & 77 \\
\hline Do practice/sample exams & 20 & 28 & 27 & 75 \\
\hline Make a study friend(s) & 18 & 13 & 5 & 36 \\
\hline Use the tutors* & 5 & 11 & 16 & 32 \\
\hline Go to office hours & 7 & 10 & 10 & 27 \\
\hline Ask questions; ask for help (general) & 5 & 8 & 3 & 16 \\
\hline Don't buy the book & 3 & 6 & 5 & 14 \\
\hline Read/use the book & 2 & 2 & 2 & 6 \\
\hline
\end{tabular}

The previous study illustrated that students who have taken a class for one or two semesters from a professor can offer valuable information to their subsequent classmates. Further, utilizing classroom management tools such as BlackBoard.com ${ }^{\mathrm{TM}}$, it is easy for the professor to pass this advice to his incoming class. Unlike university administered student evaluations of their teachers, the audience described in this study is future students. In addition, since the sample size is large and the student's comments are directed to a subsequent class, the advice is much more reliable than what is available on websites such as RateMyProfessor.com.

There are two important questions about forwarding advice from experienced students onto an incoming class. First, do the students read the advice that is sent to them before class starts? Second, do they take this advice seriously? This current paper addresses both of these issues.

\section{THE PHYSICS CLASSES IN THIS STUDY}

Like almost all other universities, Central Michigan offers a full-year introductory algebra based course that is a significant department service course. The students in College Physics I and II are the subjects of this study. In a typical year over 180 students are enrolled during the winter semester in two sections of College Physics I. In the following fall semester, 120 students are enrolled in one section of College Physics II. The profile of these CMU 
physics students is displayed in Table 2 and is similar to what one might find in a college physics course at many universities.

\begin{tabular}{|l|c|c|c|c|}
\hline \multicolumn{5}{|c|}{ Table 2 } \\
Demographics, academic information, and technology experience survey data for 119 students in the fall 1998 semester. \\
\hline CLASS & $36 \%$ & $29 \%$ & $26 \%$ & $10 \%$ \\
& Seniors & Juniors & Sophomores & Freshmen \\
\hline \multirow{2}{*}{ MAJOR } & $34 \%$ & $27 \%$ & $18 \%$ & $8 \%$ \\
& Health Fields & Biology & Industrial Technology & Physical Sciences \\
\hline \multirow{2}{*}{ MATH LEVEL } & $22 \%$ & $36 \%$ & $42 \%$ Calculus & \\
& Algebra & Pre-calculus & & \\
\multirow{2}{*}{ HS PHYSICS } & $67 \%$ & $33 \%$ & & \\
& Yes & No & & \\
\hline \multirow{2}{*}{ GENDER } & $51 \%$ & $49 \%$ & & \\
\hline MEAN GPA & Female & Male & & \\
\hline
\end{tabular}

There are no physics majors or minors in the college physics classes. With the exception of a handful of students who take College Physics I for their general education science requirement, they are all required to take the class as a requirement for their natural science major or pre-professional program. About half the students are in pre-medical, pre-dental, pre-veterinary, and pre-physical therapy programs. College physics, along with organic chemistry, physiology, and human anatomy, are prime "filter" classes used by medical professional programs in their admissions evaluations.

The students are aware that their college physics grades will be an important deciding factor in their postundergraduate career. As a result, they are highly motivated to get a good grade and they are willing to work hard in class, but they are also a demanding group of students to teach. The experienced students who wrote the advice came from the Fall 2007 College Physics II class. The class average of the one hundred-twelve students in this group was 2.44. Their advice was passed to one hundred eighty-four College Physics I students who received an average GPA of 2.33 in their course.

On the first day of class the syllabus is distributed and discussed. Students are given ample time to ask questions regarding all course policies. This syllabus contains all the standard information as suggested by Altman,1989; Birdsall, 1989; Lowther et al., 1989; Wilkerson and McKnight, 1978. The syllabus starts the important task of communicating expectations to the students (Eberly et al., 2001). These expectations must be realistic (Davis, 2006) and understandable to the students (Boice, 2000 and Felder et al., 2007). Also, it is crucial that this be communicated with immediacy (Boice, 2000). In addition, the students are given advice and encouragement for success, and they are shown how well their peers have done during previous years in this same course (Davis, 2006).

Finally, there is a "Final Words" section which gives tips and encouragement for the students to succeed in the physics class. Included are recommendations to work together, to not procrastinate in homework, and do not be afraid to ask for help from the professor and physics tutors. For twenty-eight years the professor (JF) has wondered what the students absorb this first day.

\section{RESULTS FROM THIS STUDY}

Advice from sixty-two students in the fall 2007 College Physics II class was collected the week before final exams. Using BlackBoard.com ${ }^{\mathrm{TM}}$ this advice, along with the syllabus, was distributed on December 26, 2007 to the incoming 2008 spring semester College Physics I students. The advice is prefaced by one of the authors (JF) with the following statement: 
"At the end of the fall 2007 semester I asked the students to give advice to future college physics classes. What they have to say is sincere and right on the mark. Here are their unedited (their spelling and grammar) responses..."

At the beginning of the second week of the 2008 spring semester the College Physics I students were asked if they read the advice from the previous students. One hundred-sixty students replied and estimated the number of comments they read. Their response rate is shown in Table 3. Ninety percent of the students read at least half of the comments and only three students did not take the time to even glance at the advice. Clearly, the overwhelming majority of students were interested in what their experienced peers had to say about the class they were beginning.

\begin{tabular}{|c|c|}
\hline \multicolumn{2}{|c|}{ Table 3} \\
College Physics I students who read the comments about the class written by College Physics II students. \\
\hline What percent of the comments from last semester's class did you read? & \#Number of responses \\
\hline $100 \%$ & 41 \\
\hline $75 \%$ & 68 \\
\hline $50 \%$ & 35 \\
\hline $25 \%$ & 13 \\
\hline Zero. I knew about this but did not read any comments. & 3 \\
\hline Zero. I did not know about this. & 0 \\
\hline
\end{tabular}

Table 1 summarized the ten most common pieces of advice given by students to their incoming peers. These are further combined in Table 4 to give six general areas. One week before the end of the semester one hundred forty-three students were asked to what degree they followed the advice given to them by the previous class. Clear majorities either strongly agreed or agreed that they did not procrastinate with homework (76\%) and did all the homework $(61 \%)$. It should be noted that there were 251 homework problems which counted for one-quarter of their grade. Similarly, $92 \%$ and $83 \%$ of the students, respectively, followed the advice to go to class every day and to practice sample exams.

There were two areas where students admitted not following the advice of the previous class. Only $18 \%$ strongly agreed or agreed that they used the free help room tutors, and, correspondingly, only $13 \%$ made frequent use of the professor's office hours. The under use of office hours is disappointing. The professor in this course (JF) has four hours available to students in his office. Two hours a week in the College of Science and Technology residential hall are also open to all students. In addition, the professor (JF) has an "open door" policy outside of posted office hours and encourages students to make appointments at any time.

\begin{tabular}{|c|c|c|c|c|c|}
\hline \multicolumn{6}{|c|}{$\begin{array}{c}\text { Table } 4 \\
\text { Degree to which } 144 \text { students followed the advice of their experienced peers. }\end{array}$} \\
\hline Advice & Strongly agree & Agree & Neutral & Disagree & Strongly Disagree \\
\hline Do not procrastinate with homework & 108 & 25 & 6 & 2 & 2 \\
\hline Do all the homework. & 52 & 34 & 27 & 25 & 5 \\
\hline Go to class every day. & 100 & 29 & 8 & 3 & 0 \\
\hline Do sample exams. & 88 & 28 & 11 & 7 & 5 \\
\hline Use the help room & 16 & 10 & 17 & 20 & 76 \\
\hline Go to Dr. Finck's office hours. & 7 & 11 & 30 & 22 & 69 \\
\hline
\end{tabular}

One week before the end of the semester the students were also asked to reflect back on the previous fourteen weeks and, whether or not they followed the advice of the previous class, did they give good advice. Table 5 shows that the students overwhelmingly strongly agreed that they should not have procrastinated on homework, they should have done all the homework and they should have gone to class every day. This certainly confirms that 
the advice given by the previous class was sound and worthwhile. In addition, over half the class strongly agree or agree that it was good advice to use the help room and only $13 \%$ did not think this was good advice. Perhaps the most significant result was that at the end of the semester $64 \%$ realized the value of going to office hours, while $28 \%$ were neutral and $8 \%$ did not believe they would have benefited from going to the professor's office hours.

Table 5. One week before the end of the semester the students were asked to reflect back on the previous fourteen weeks. Whether or not they heeded the suggestions, was it good advice?

\begin{tabular}{|l|c|c|c|c|c|}
\hline \multicolumn{1}{|c|}{ Advice } & Strongly agree & Agree & Neutral & Disagree & Strongly Disagree \\
\hline Do not procrastinate with homework & 136 & 1 & 1 & 0 & 0 \\
\hline Do all the homework. & 113 & 19 & 6 & 1 & 1 \\
\hline Go to class every day. & 128 & 8 & 1 & 0 & 0 \\
\hline Do sample exams. & 116 & 13 & 10 & 2 & 0 \\
\hline Use the help room & 46 & 25 & 51 & 7 & 11 \\
\hline Go to Dr. Finck's office hours. & 57 & 33 & 40 & 6 & 5 \\
\hline
\end{tabular}

The last set of questions the students were asked at the end of the semester addressed if they appreciated receiving information from the experienced students and if this practice should be continued for future students. Table 6 shows that $98 \%$ of the students were supportive of both. This certainly confirms the value of having experienced students pass advice on to the following class.

Table 6

One week before the end of the semester the students were asked to rate two general statements about receiving advice from the previous class.

\begin{tabular}{|l|c|c|c|c|c|}
\hline & Strongly agree & Agree & Neutral & Disagree & Strongly Disagree \\
\hline $\begin{array}{l}\text { I appreciated receiving information about this } \\
\text { college physics class before the start of the } \\
\text { semester. }\end{array}$ & 105 & 33 & 3 & 0 & 0 \\
\hline $\begin{array}{l}\text { The professor should continue this practice of } \\
\text { soliciting information from experienced } \\
\text { students and passing it on to incoming } \\
\text { students. }\end{array}$ & 107 & 31 & 3 & 0 & 0 \\
\hline
\end{tabular}

\section{CONCLUSIONS AND SUGGESTIONS FOR FURTHER STUDIES}

Before class begins students will look at RMP and talk to peers who have taken the class or professor, and wonder if the advice can be trusted. On the first day of class the professor will distribute the syllabus, answer questions about the class, encourage them to work hard, and wonder if the students are paying attention to anything he or she is saying. It would clearly be valuable to students to receive advice from many peers who have taken this class from this professor, and to have this information available before the first day of class.

Our previous paper (DeLine \& Finck, 2008) illustrated that students who have taken a class for one or two semesters from a professor can offer valuable information to their subsequent classmates. Further, utilizing classroom management tools such as BlackBoard.com ${ }^{\mathrm{TM}}$, it is easy for the professor to pass this advice to his incoming class. Unlike university administered student evaluations of their teachers, the audience described in this study is future students. In addition, since the sample size is large and the student's comments are directed to a subsequent class, the advice is much more reliable than what is available on websites such as RateMyProfessor.com. 
In this paper we showed that the students who were sent suggestions from their experienced peers did read it and took the advice to not procrastinate on the homework, do all the homework, go to class every day and make use of sample exams. However, throughout the course of the semester they took limited advantage of the professor's office hours and the physics help room. This was in spite of the encouragement of the previous class to do so and even their own recognition at the end of the semester that these were missed opportunities..

Finally, the students were very appreciative that the previous class wrote tips for them to succeed and that the professor made this available to them before the start of the semester. And they overwhelmingly agreed that the practice should continue, even given the realization that they would be asked to give their subsequent class in the future.

\section{REFERENCES}

1. Ahmadi, M., Helms, M. M., \& Raiszadeh, F. (2001). "Business students' perceptions of faculty evaluations." The International Journal of Educational Management, 15 (1), 12-22.

2. Boice, R., Advice for New Faculty Members Nihil Nimus. Boston: Allyn and Bacon, 2000.

3. Centra, J. A. (2003). "Will teachers receive higher student evaluations by giving higher grades and less course work?" Research in Higher Education, 44, 496-518.

4. Cooladarci, T., and Kornfield, I. "RateMyProfessors.com versus formal in-class evaluations of teaching." Practical Assessment, Research \& Evaluation, 2007, 12(6), 1-13.

5. $\quad$ Davis, B. G., Tools for Teaching. Jossey-Bass Publishers: San Francisco, 2006.

6. Davison, E. and Price, J. "How Do We Rate? An Evaluation of Online Student Evaluations." Department of Sociology and Social Work, Appalachian State University, August 2006. This article may be retrieved via the following URL: (http://www1.appstate.edu/ pricejl/TEACHING/methods/RMP_8_06.pdf).

7. DeLine, A. D. and Finck, J. E., "Students Giving Students Advice before the First Day," College Teaching Methods \& Styles Journal, 2008, 4(5), 29-38.

8. $\quad$ Eberly, M. B., Newton, S. E., and Wiggins, R. A. "The syllabus as a Tool for Student-Centered Learning." The Journal of General Education, 2001, 50 (1), 56-74.

9. $\quad$ Felder, R. M., and Brent, R. "How to Prepare New Courses While Keeping Your Sanity." Chem. Engr. Education, 2007, 41(2), 131-122.

10. Hobson, S. M., and Talbot, D. M. "Understanding Student Evaluations.” College teaching, 2001, 49(1), 26-31.

11. Kindred, J. \& Mohammed, S. N. (2005). “'He will crush you like an academic Ninja!’: Exploring teacher ratings on Ratemyprofessors.com." Journal of Computer-Mediated Communication, 10(3).

12. (Knefelkamp,L.) In Rubin, S. "Professors, Students, and the Syllabus," The Chronicle of Higher Education, August 7,1985, 85.

13. Montell, G. A. "The art of the bogus rating." The Chronicle of Higher Education, September 27, 2006. Retrieved November 22, 2006, from (http://chronicle.com/jobs/news/2006/09/2006092701c/careers.html).

14. Otto, J., Sanford, D. A., and Ross, D. N. "Dose ratemyprofessor.com really rate my professor?" Assessment \& Evaluation in Higher Education, 2008, 33(1), 1-16.

15. RateMyProfessors.com, 2007. Retrieved June 2, 2007 from the following URL: (ratemyprofessors.com/About.jsp).

16. Sallee, M. W. and Tierney, W. G. "The Influence of Peer Groups on Academic Success," College and University Journal, 2007, 82(2), 7-14.

17. Smith, R. A. and Peterson, B. L., "'Psst... What Do You Think?" The Relationship between Advice Prestige, Type of Advice, and Academic Performance," Communication Education, 2007, 56(3), 278-291. 